\title{
Climate change adaptation in rural South Africa: Using stakeholder narratives to build
} system dynamics models in data-scarce environments

\author{
Carnohan, Shane ; Clifford-Holmes, Jai K.; Retief, Hugo; McKnight, Ursula S.; Pollard, Sharon
}

Published in:

Journal of Simulation

Link to article, DOI:

$10.1080 / 17477778.2020 .1762516$

Publication date:

2021

Document Version

Peer reviewed version

Link back to DTU Orbit

Citation (APA):

Carnohan, S., Clifford-Holmes, J. K., Retief, H., McKnight, U. S., \& Pollard, S. (2021). Climate change adaptation in rural South Africa: Using stakeholder narratives to build system dynamics models in data-scarce environments. Journal of Simulation, 15(1-2), 5-22. https://doi.org/10.1080/17477778.2020.1762516

\section{General rights}

Copyright and moral rights for the publications made accessible in the public portal are retained by the authors and/or other copyright owners and it is a condition of accessing publications that users recognise and abide by the legal requirements associated with these rights.

- Users may download and print one copy of any publication from the public portal for the purpose of private study or research.

- You may not further distribute the material or use it for any profit-making activity or commercial gain

- You may freely distribute the URL identifying the publication in the public portal 


\section{Climate Change Adaptation in Rural South Africa: Using Stakeholder Narratives}

to Build System Dynamics Models in Data-scarce Environments

3 *Shane A. Carnohan ${ }^{\text {a,b,e }}$, Jai K. Clifford-Holmes ${ }^{c, d}$, Hugo Retief ${ }^{d}$, Ursula S.

4 McKnight $^{a}$, Sharon Pollard ${ }^{\mathrm{d}}$

$5 \quad{ }^{a}$ Department of Environmental Engineering, Technical University of Denmark, Bygningstorvet, Building

6 115, 2800 Kgs. Lyngby, Denmark

$7 \quad{ }^{b}$ Sino-Danish Center for Education and Research (SDC), University of Chinese Academy of Sciences, 380

8 Huaibeizhuang, Beijing, China

9 'Institute for Water Research, Rhodes University, P.O. Box 96, Grahamstown, 6140, South Africa

$10{ }^{d}$ Association for Water and Rural Development (AWARD), P.O. Box 1919, Hoedspruit, Limpopo, 1380,

11 South Africa

$12 *$ Corresponding author email: shca@env.dtu.dk 
The need for innovative approaches incorporating combinations of human and natural pressures for governing and managing water resources more systemically is well established. Participatory modeling has been found to support stakeholder involvement and integrated analysis. However, the uptake of systemic participatory modeling tools within high-conflict, data scarce contexts - especially in the developing world - has been limited. The need for participatory, systemic approaches is essential for addressing deteriorating water resources globally. This study uses narratives to build a system dynamics (SD) model, ResiMod, within a participatory process. The novel participatory modelling process was driven by challenges facing the lower Olifants River Catchment in South Africa, including; exceedance of sulphate and phosphate concentration limits, paucity of numerical data and a high-conflict stakeholder mix. This paper demonstrates how narratives can inform, and be informed by iterative model development. ResiMod enabled the exploration of perceptions of causality, connections between stakeholder sectors, and potential mitigatory actions that respond to climate-change driven impacts to biodiversity. Furthermore, the process enabled cutting-edge scientific discoveries to be incorporated alongside learning and management insights. The combination of narratives and SD modeling offers a promising approach to support improved communication and learning in high-conflict, data-scarce contexts. 


\section{Introduction}

The complex interplay between human needs for water as an essential natural resource and contamination of land and water resources from anthropogenic activities is a global challenge. Recent research from the World Economic Forum (2020) indicates that water crises represent society's greatest challenge, placing them among the top ten global risks. Contamination generated at industrial sites, such as chemical production facilities and large-scale mining complexes, is often perceived as a widespread infrastructural problem compounded by the fact that mitigation of any adverse impacts can be economically challenging (Rügner et al., 2006; McKnight \& Finkel, 2013). For example, impacts from acid mine drainage (AMD) produced by mining activities are highly variable as AMD is a product of an array of site-specific properties, which makes predicting the potential for AMD exceedingly challenging and costly (Akcil \& Koldas, 2006). Further, systems characterized by a heterogeneous patchwork composed of natural, rural and urban land usage (i.e. peri-urban) are challenging to assess, due to the variety of chemical inputs entering streams, stemming from e.g. agriculture and waste water treatment works (WWTW) (Lemaire et al., 2020; Sonne et al., 2017).

Water resources that are directly threatened by human activities also stand to be further affected by anthropogenic climate change, and devising interventions that will protect freshwater biodiversity and ensure the sustainability of water delivery systems requires frameworks capable of diagnosing the key threats to water security at a range of scales (Sonne et al., 2018; Vörösmarty et al., 2010). As such, there is a need for more systemic approaches that can incorporate the combinations of pressures and their potential intended and unintended consequences, especially where integrated water resources management (IWRM) is concerned (van den Belt \& Blake, 2015). The progression of climate change poses significant challenges especially to the IWRM sector of South Africa. The expected impacts include increases in temperature and increased frequencies of severe rain events and periods of drought (Kusangaya et al., 2014) and up to a 60\% decline in water yield along the eastern border with

62 Mozambique (Schulze \& Davis, 2019). These impacts to natural systems are compounded by both a society struggling with the legacy of post-apartheid inequality and a developing economy (S. Pollard et al., 2014). These interlinking aspects produce a raft of complex management challenges within the water management sector, potentially at a greater scale than is seen in other areas of governance within South Africa (Ziervogel et al., 2014). A substantial and growing body of scientific research has

67 sought to inform adaptive management strategy in the country (Clifford-Holmes, Carnohan, Biggs, 
there remains a significant gap between knowledge and implementation - with institutional barriers and poor collaboration playing a key role (Koelble \& Siddle, 2014; Mehta et al., 2014; Ziervogel et al., 2014). Notably, this gap between scientific assessment and policy implementation has been identified worldwide as a critical barrier to achieving environmental policy goals affecting water resources (Carvalho et al., 2019).

Recognition of the roles institutions and individuals (e.g. stakeholders) play in the implementation of water management strategies has also been in focus globally, featuring in multiple initiatives including the European Water Framework Directive, U.S. Clean Water Act, and the UN Sustainable Development Goals. With respect to water resources, participatory modeling processes "have been found to be a useful methodology to support stakeholder involvement and ensure a more integrated analysis" (Halbe et al., 2018). Participatory modeling has been applied to water resource challenges for more than two decades (Ford, 1996) with increasing application globally (Antunes et al., 2009; Langsdale et al., 2013; Pahl-Wostl, 2015; Stave, 2003; van den Belt \& Blake, 2015).

System dynamics (SD) is a modeling practice with a long history of application to IWRM, and its application is increasing (Khan et al., 2009; Winz et al., 2009). SD is a technique that simulates system behaviour based on the servo-mechanical principles of accumulation, delay and feedback (Sterman, 2000). The transparency (Beall et al., 2011) and flexibility (Winz et al., 2009) of SD has led to established and effective participatory methodologies (Rouwette et al., 2002; Rodney James Scott et al., 2016; Vennix, 1999). However, barriers remain that limit further expansion of participatory SD approaches within IWRM, including time demands of stakeholder engagements, context-specificity and short timeframe of participatory modeling interventions (Halbe et al., 2018). Responding to these challenges requires further alterations to methodologies, improving the adaptability of participatory SD to the physical, environmental, socio-economic and institutional circumstances (ibid.).

The work reported here draws upon a method which aims to pragmatically adapt participatory SD tools to the "messy operational reality" faced by stakeholders (Clifford-Holmes, Slinger, de Wet, \& Palmer, 2018). This approach is used to support novel integration of narratives (i.e. storytelling) to support the development and application of a SD model, ResiMod, within a participatory process. The model was developed to support the component action research project known as Collaborative Dynamic Modeling (CoDyM). The primary aims of ResiMod were to: (1) integrate perspectives of multiple, diverse stakeholders; (2) improve stakeholder understanding and consideration of possible 
climate change impacts; and (3) uncover and communicate learning and management insights through the model-building process and through the resulting simulations (Clifford-Holmes, Carnohan, et al. 2016; Clifford-Holmes, Pollard, et al. 2016).

\section{Olifants River Catchment study site}

The Selati River traverses an important sub-catchment located within the transboundary Olifants River Catchment (ORC) in the Limpopo Province of South Africa. The Association for Water and Rural Development (AWARD) initiated the participatory SD process as part of the USAID-funded Resilience in the Limpopo-Olifants basin (RESILIM-O) programme, which aims to improve resource management in the ORC. The catchment is beset with diverse management challenges: the need to improve water security must be balanced within a contested governance context, which currently faces severe capacity constraints. These capacity constraints affect physical and operational capacity for water sanitation services (Department of Water Affairs, 2011; Kings, 2017). Of the estimated 120 WWTWs in the ORC, many do not comply with national benchmarks. Of those assessed for waste-water quality compliance in 2011 in the case study area, compliance was only achieved 20\% of the time (Hansen \& Pollard, 2015). Additional constraints include a lack of 'clean-up' funding allocated to ageing mining and industrial sites and weak enforcement and implementation of environmental regulations (Dippenaar et al., 2005). Stakeholders span agriculture, mining and industry, conservation and municipal water supply and sanitation.

Existing models have been used in the ORC to investigate water quality parameters indicitave of the activities of these stakeholder groups (e.g. sulphate, phosphate, nitrate) (Slaughter et al., 2017). However, the diversity of roles and governance levels within and among these stakeholder groups leads to difficulty in navigating conflict-riddled communication pathways, hampering efforts to reconcile crises

121 occurring across the catchment (Clifford-Holmes et al., 2016; S. Pollard \& Laporte, 2015). The overall

122 problems faced become even more vexing when water security is considered in the context of the 123 potential effects of climate change, where the ORC is projected to experience higher temperatures and 124 intense rain events (Climate System Analysis Group (CSAG), 2016; Pollard et al., 2020). When this 125 amalgamation of pressures is considered, there is a clear need for novel approaches to support adaptive 126 catchment-based management across time-scales (Clifford-Holmes, Pollard, et al., 2016; Pollard \& 127 Laporte, 2015). 
The Selati River joins the Olifants River before passing through Kruger National Park (KNP), and

crossing into Mozambique (Figure 1). KNP is internationally renowned as a beacon of biodiversity but its downstream location makes it highly vulnerable to impacts from the upstream activities of multiple actors along the Selati. To date, various contaminant inputs along the Selati and elsewhere in the catchment have had negative impacts on KNP biodiversity (Centre for Environmental Rights (CER), 2016). Earlier work scoped supported the identification of stakeholders that should engaged in building ResiMod (Clifford-Holmes et al., 2016). Priority stakeholders were identified from the Ba-Phalaborwa wastewater treatment works (WWTW), Phalaborwa Mining and Industrial Complex (PMIC), and Kruger National Park (conservation).

Figure 1. Hydrological boundaries of the Selati Catchment of the Limpopo basin, South Africa.

\section{Methodology}

A blend of approaches and tools was used to build ResiMod, emerging out of necessity due to the characteristics of the case study site including a restrictive timeline (three months) for completion of the field work within the RESILIM-O project. The paucity of written and numerical data to draw from, resulted in an increased dependency on stakeholders' knowledge of the catchment in order to define the structure of the system and support interpretation of the resulting model behaviour. SD was chosen as the main modelling method due to (i) its suitability for exploring long time frames ( $50 \mathrm{yr}$ ); (ii) ability to deliver insights about the non-linear system-wide interactions that may lead to unintended consequences, and (iii) its patent focus on espousing the relationship between system structure and behaviour (Forrester \& Senge, 1980). These characteristics developed into several participatory disciplines - granting access to a diverse library of tools for stakeholder engagement. SD was therefore preferred, given the long time-horizon under consideration (with respect to climate change), as well as the diverse levels of expertise of the stakeholders. Furthermore, complex spatial interactions, where other methods excel (e.g. agent based modelling), were not a focus of this study (Voinov et al., 2018).

\subsection{Narratives and System Dynamics}

The concept of applying narratives (i.e. stories) to communicate scientific insights has been increasingly explored (Avraamidou \& Osborne, 2009; Dahlstrom, 2014; Krzywinski \& Cairo, 2013). The definition of narrative communication is often given in relation to Bruner's 1986 framework for how 
humans organize information (Avraamidou \& Osborne, 2009). Bruner's framework differentiated between paradigmatic, or reason-based, logical, scientific constructions, and narrative, which "refer[s] to a way of sculpting and structuring information [...] into readily understood forms that guide learners' comprehension" (Avraamidou \& Osborne, 2009). Where paradigmatic communication strives for generalizability and being context-independent, narrative is specific and context-dependent (Dahlstrom, 2014). Narratives have previously been viewed in a poor light, as they are inherently persuasive and can therefore be manipulative (Dahlstrom, 2014; Katz, 2013). However, the strengths of narratives have also been examined, for example, Tsoukas and Hatch (2001) argue that narrative modes of communication take into account context, human agency within that context, and temporal characteristics, which are absent from paradigmatic communication. This is a crucial factor when analysing decision scenarios in complex problem spaces. Furthermore, the inclusion of these characteristics can be used to support linkages between system elements (Tsoukas \& Hatch, 2001) and, by extension, between actors and the system under observation (Flyvbjerg, 2004).

The benefit of blending narratives and simulation has been explored using a variety of modeling approaches. Alcamo (2008) developed a framework and approach called "storylines and simulation" (SAS), aimed at coupling quantitative models with qualitative narratives. Drawbacks to SAS include the time-intensiveness of the development process for both aspects (narrative; simulation), inflexibility of modeling approaches, and challenges with reproducibility due to lack of transparency. Following the SAS framework, recent participatory modeling studies have used approaches to combine narratives and simulation successfully. For example, Houet et al. (2016) apply narratives using several models at multiple scales. However, they note limitations related with the application of their approach to developing country contexts and argue for more participation with stakeholders.

Participatory SD has historically sought to align participants' mental models, or "relatively enduring and accessible, but limited, internal conceptual representation[s]" (Scott et al., 2014), using SD simulation models and structured processes. Mental models and narratives are quite similar in their definition. For example, Oatley (1999) likens a narrative to a "simulation that runs on minds of readers just as computer simulations run on computers." SD modeling as a method and discipline exposes the relationship between individual agency (decisions) with the operations of the system at-hand (Olaya, 2015). 
The use of SD modeling in a participatory fashion can stimulate cognitive conflict, a beneficial aspect for improving the quality of group decisions (Vennix, 1996) and allowing all individuals a chance to take part in the discussion, which promotes consensus-building (Korsgaard et al., 1995). Our approach to building ResiMod utilizes both of these aspects, aiming to build consensus by incorporating diverse stakeholder narratives into the model and use the resulting simulations to challenge their mental models (i.e. cognitive conflict). In this way, we sought to challenge individual views in order to support consensus-building and communication among the larger group.

In summary, the development of ResiMod is distinguished by the explicit integration of narratives as key inputs into the participatory SD modelling process (see Figure 2). This is a novel approach which has been relatively unexplored (Guhathakurta, 2002; Mallampalli et al., 2016). Furthermore, the similarity of narratives and mental models makes SD a preferable tool to explore this integration - due to the established effectiveness of participatory SD modelling in creating enduring changes to mental models (Scott et al., 2016).

\subsection{The "Muddled Middle" Approach}

The approach to model building and stakeholder engagement was rooted in the "modeling in the muddle middle" or $\mathrm{M}^{3}$ approach, which integrates ethnographic, institutional and systems analyses, recognizing that modeling can serve many purposes from supporting process to delivering analytical results (Clifford-Holmes et al. 2018). The $\mathrm{M}^{3}$ approach allows for construction of multiple smaller submodels, following best-practice SD modeling (Ford, 2010; Sterman, 2000). With ResiMod, initial causal loop and stock-and-flow (SF) diagramming set the stage for parameter estimation and simulation. The $\mathrm{M}^{3}$ approach was adopted to fit the socio-political context, which is "characterised by multiple conflicting users who are divided along multiple lines (racial, ethnic, economic and nationality)" (Clifford-Holmes et al., 2018; Zolfagharian et al., 2018). During the problem scoping phase of the modeling process, focus shifted towards the lower-Olifants, where some of the greatest impacts to water quality had been experienced, in the form of sulphate and phosphate concentrations exceeding legislated values (Clifford-Holmes, Pollard, et al. 2016). For the construction of sub-models, stakeholders were divided into common interest groups and meetings were conducted both individually and in groups (Table 1). Such a strategy has been successfully applied previously in case study settings using SD, where diverse "fragmented" stakeholders are represented in the process (Eker et al., 2018). 


\section{$217 \quad 3.3$ Integrating Narratives and Participatory SD}

Within the individual working sessions (see Table 1), simple concept models were often introduced using a stock and flow diagram (SFD) (see Table 2) (Richardson, 2013). However, this was not always possible or useful due to time constraints, or challenges in conveying the message through diagrams. For these situations, an unstructured interview strategy was chosen, since this method is regarded as advantageous for eliciting participants' own reality as a means to develop theory (Fontana

223 \& Frey, 2005). In these sessions, a combination of causal loop diagrams (CLD) and hybrid SFDs along with

224 field notes were used to capture the narratives. Sessions typically lasted from 1-3 hours, and towards 225 the end of the interview, the CLD/SF diagram would be reflected back to the stakeholder in narrative 226 form in order to verify that it captured the discussion appropriately.

Table 2. Diagrammatic conventions used in this paper for the stock and flow diagrams (SFDs). Table adapted from (CliffordHolmes et al. 2017).

In follow-up interviews, the disconfirmatory interview strategy was applied to test/verify the developing theory. This strategy includes anchoring participants in specific content based upon their expertise, adapting the interview to the participant, and organizing the interview around the model

232 structure and behaviour. As the narratives and model developed, they could be presented and acknowledged as works-in-progress that may have errors (Andersen et al., 2012). The use of the disconfirmatory interview responds to ethical concerns relating to the inherent persuasiveness of narratives (Dahlstrom, 2014). This approach was performed iteratively, and accumulating information was shared in the sessions that followed. This enabled the exploration of connections between sectors and allowed the perspectives of stakeholders from different sectors to be shared. Thus, narratives both informed, and were informed by the model development.

\subsection{Modeling integration and Climate Change}


quantity and quality data were taken from WQSAM, which simulates water quality by receiving flow volumes from a yield model - the Water Resources Modeling Platform (WReMP). The WReMP delivers flow data on a monthly basis, which is disaggregated in WQSAM into a daily time-step to capture transient events required when modeling diffuse and variable loads. (see Slaughter et al. (2017; 2013)). The WReMP model provides WQSAM with monthly flow data as incremental stream flows and return

250 flows. This monthly flow undergoes two transformations; first it is disaggregated to a daily timestep, using observed and simulated (CC) rainfall allowing us to capture transient events (e.g. sulphate mobilisation from a runoff event on a mine). The daily discharge is then separated into surface, interflow and groundwater flow components; this allows us to route pollutants (water quality) along these pathways. Non-point source pollutants are routed through surface, interflow and groundwater while point sources are routed through return flows. By providing the ResiMod with return flow volumes and the receiving river quality and quantity, the end fate load and concentration can be determined and

257 altered according to an intervention strategy, which was calculated by integration with ResiMod (further detailed in the results).

The climate modeling was performed by the Climate System Analysis Group who statistically downscaled climate projections from three General Circulation Models (GCMs), representing medium and high greenhouse gas concentration (not emission) trajectories (Climate System Analysis Group 262 (CSAG), 2016)). In ResiMod, only the downscaled projection for RCP8.5 and the MIROC-ESM GCM was used. The same climate projections were utilised in the WReMP yield model and WQSAM. Importantly, these models and other assumptions regarding the impact of climate change (CC) within ResiMod were used to develop a "CC switch". This activates a suite of parameter changes, as shown in Table 3.

Table 3. The CC switch engages multiple parameters informed by multiple information/data sources.

\section{Results and Discussion}

Narrative results are presented, followed by their implementation into the SD structure. Discussion of key assumptions and data sources are given for each sector alongside the corresponding

270 structure.This section thus provides a detailed description of the model logic, establishing the 271 conceptual foundation that was constructed iteratively using the narrative approach. This includes key 272 stocks, flows and feedback loops alongside important parameter assumptions provided by participants 273 or the modelling team (Monks et al., 2019). Following the STRESS-SD guidelines for model reporting 
274 (ibid.), additional parameters, equations and detailed descriptions of data sources are provided in

275 Supplementary Document 1.

\section{$276 \quad 4.1$ Mining and litigation}

277

278

279

280

281

282

283

284

285

286

287

288

289

290

291

292

293

294

295

\subsubsection{Narrative}

Mining tailings waste is a well-known threat to freshwater biodiversity, with seepage and spills delivering sulphates to the Olifants River. Although elevated levels of sulphates can directly impact biodiversity, their persistent presence in water resource systems can indicate that other types of pollutants (e.g. heavy metals) are entering and accumulating in the aquatic ecosystem. Other toxic compounds can enter the stream when spills occur, brought on by flooding which will likely increase under climate change conditions. Spills can have broad negative consequences for the PMIC's bottom line. This is due to media reporting on impacts to biodiversity in the KNP, which can generate public awareness. Past events have shown that mining companies respond more strongly to public awareness pressure than to regulatory pressure. Similarly, impacts to biodiversity generate more public awareness than regulatory exceedances. There are delays in response time before the media disseminates the information to the broader public. While some measures have been taken to prevent these outcomes (e.g. reusing process water) there are still many opportunities for mining companies to mitigate these outcomes. There is an important distinction between reactive mitigation (i.e. after pollution event and regulatory action) and proactive mitigation (i.e. before pollution event and regulatory action), with the former carrying additional costs through fines and reputational damage. On the other hand, mining companies can proactively develop policies to mitigate the negative environmental consequences of tailings-waste and improve their institutional memory, embedding lessons learned from previous regulatory punishments.

\subsubsection{SD structure and parameterization of mining sector}

Figure 3 presents the structure and main stocks of the mining sector. The representation of "tailings mitigated" and "unmitigated tailings of PMIC" simplify the fate of tailings-waste. Any unmitigated tailings are representative of the volume of tailings assumed to be prone to seepage and spills, and when tailings are 'mitigated' they can no longer enter the environment. Mitigation is therefore a representation of all the possible activities that may be undertaken by the PMIC to prevent any further release into the environment. A significant assumption is that the model considers these 
activities would be $100 \%$ successful. This point was initially contested by mining company representatives in a working session, however, further discussion led to agreement that this structure and aggregation level could ultimately represent the effects of their mitigation efforts.

Figure 3. The stock-flow structure of the mining sector separates the volume of tailings (in megalitres) into unmitigated and mitigated fractions. A third stock is used to track the total amount of sulphate (measured in tonnes) released from the dam over the 50-year period.

The "process water reuse" flow was included in order to show PMIC representatives that the modeling team was aware of their efforts to mitigate environmental impacts. The fraction "proportion of tailings water reused" determines both flow rates, as the remaining fraction sets the amount of "water diverted into tailings dam" each month.

A constant value for the "fractional seepage rate" was adopted from earlier modeling work (Jonker et al., 2015). Total sulphate discharge is the product of "seepage" volume and the "sulphate concentration of seepage". There is an assumption made here that all seepage enters the stream; ResiMod does not distinguish between specific transport pathways. There was a broadly communicated perception of many stakeholders that mining tailings waste has a great impact to the freshwater ecosystem. International headlines reflected this as well, following the 2013/2014 spill events (Centre for Environmental Rights (CER), 2016). In ResiMod, impact was based upon the use of a preliminary species sensitivity distribution (SSD) developed for combined sulphate salts (e.g. Dowse, Tang, Palmer, \& Kefford, 2013). Sulphate is recognised as a key component that may additionally influence which processes/fluxes occur in conjunction with contaminant release dynamics (Rinklebe et al., 2016). Notably, these curves have subsequently been revised, as sulphate salts were found to be more toxic than the preliminary data had shown (Vellemu et al., 2017).

An additional stock tracking the accumulation of tonnes of sulphates was added. This was motivated by input from conservation sector stakeholders, who felt that the long-term bioaccumulation of sulphate salts pose an additional threat. The stock variable "Total tonnes of sulphate released over 50 years" was used as a means of promoting conversations about the possible long-term systemic impacts. 


\subsection{WWTW Sector}

332

333

334

335

\subsubsection{Narrative}

Population growth leads to increasing demands for WWTW facilities in the local Ba-Phalaborwa municipality. However, the total operating capacity of WWTWs is constrained by the ability to maintain the actual physical WWTW capacity. It takes time to recruit and train staff to handle the required daily operation and maintenance (O\&M). Therefore, even though the overall physical capacity of the WWTW in Ba-Phalaborwa may support the population, it may not be operational due to O\&M constraints. This trend has been seen due to underinvestment in maintenance and training, in favour of investment in the physical capacity. The result is the release of phosphates into the Selati, compounded by more intense rainfall leading to flooding which overwhelms WWTW. This challenge is compounded because plants which are improperly maintained have shorter operational lifetimes, resulting in a loss of capacity and a failure to maximize on public infrastructure investment. Building new WWTW also takes time and keeping up with forecasted demand requires long-term planning. When WWTW capacity is unable to keep up with demand, excessive phosphate concentrations will then be released to the Olifants River system, adversely affecting biodiversity. This can be mitigated by improving/shortening training, improving operations, and improving maintenance to ensure available physical WWTW capacity is fully utilised.

\subsubsection{Structure and parameterization of WWTW sector}

Figure 4 presents the representation of this sector within the SD model, as "Total population in Ba-Phalaborwa" drives the demand for WWTW. Data for the 'fractional population growth rate' were derived from the Ba-Phalaborwa Municipality Census Data, (2011). The population is multiplied by "sewage per person" measured in litres (I) per day, converted to ML per month. This is the "demand for WWTW" or the amount of sewage produced per month from the "percentage of population connected" and refers to Ba-Phalabowa residents (Holness, 2014; Jonker et al., 2015).

Figure 4. The stock-flow structure showing how population drives the development of WWTW.

"Forecasted demand" is based on the current "total capacity" of WWTW. The 'time horizon' is how far into the future the demand forecast is made and a longer horizon leads to a higher forecasted 
demand. This leaves remaining 'indicated physical capacity' that should be developed in order to meet the forecasted demand. The planning horizon guidelines indicated that a horizon of 10 years is standard (Nozaic \& Freese, 2009).

Figure 5 presents the operations and maintenance (O\&M) capacity of WWTW, which was added to the model based on input from the retired WWTW supervisor and supported by literature (Gopo, 2013).

\section{Figure 5. Stock-flow structure of the WWTW O\&M capacity.}

The O\&M capacity is used to capture the overall ability of the managers, operators and general maintenance staff to operate and maintain WWTWs. Human resources were one of the main issues under scrutiny by regulators while ResiMod was under development. Stakeholders lamented that improvements are only likely over a very long time-horizon (captured in the 'time to train and update O\&M capacity' variable). Furthermore, the structure captures the WWTW consultant's indication that regulatory incentives have led to an overemphasis on increasing technical capabilities of plants without improving staff recruitment and training. The consultant validated the vicious cycle that this creates, where more failures take place along with increasing infrastructure capacity and that these failures then motivate funding applications for more physical capacity (Carrim et al., 2010; Manus \& Van Der MerweBotha, 2010).

The notion that such capacity has been largely underemphasized is a key part of the model narrative as told by many of the stakeholders in the WWTW sector. Therefore, the "hiring new O\&M capacity" is constrained by both hiring and training delays and the lack of emphasis on human resource development as "fraction of O\&M supported". The initial value estimate for this stock was developed with the WWTW policy consultant and calculated to be $60 \%$ of total WWTW capacity (see Figure 6).

The physical capacity (Figure 6) is categorized as either online, and therefore treating wastewater generated by the population, or offline, i.e. inoperable for any number of reasons. More specifically, "WWTW physical capacity online", refers to the plant's total capacity to physically process incoming sewage to meet legislative benchmarks for phosphate concentration (Requirements for the Purification of Waste Water or Effluent, 1984). For both the online and offline capacities, data for WWTW plants servicing the Ba-Phalaborwa Local Municipality (BPLM) were used to set initial values (BaPhalaborwa Municipality, 2015). 
Figure 6. Stock-flow structure of the WWTW physical capacity, including assumptions regarding the rate of failure and decommissioning.

Other key variables include the "new physical capacity", which refers to the construction of additional WWTW capacity. Capacity is added based on the forecasted demand and policy of investment as "fraction of physical development need supported". 'O\&M capacity available for maintenance' is the difference between the physical capacity online and the O\&M capacity. It assumes that operating online capacity takes an equivalent amount of O\&M. The remaining O\&M capacity is free to perform any necessary maintenance tasks driving the "repair rate of WWTW". This is adjusted by the "final infrastructure efficiency factor", which allows the user to simulate scenarios where technologically advanced WWTW plants could be installed requiring less O\&M capacity to operate effectively.

The WWTW policy consultant further described the effect of O\&M maintenance on the lifetime of the plant. In this case, she confirmed that the "ratio of O\&M to capacity" was a useful measure of the routine maintenance capability. The consultant worked directly within the model to help define the

402 graphical function for the "effect of O\&M ratio on average life of plant" and verified the behaviour of 403 the resulting simulations.

\section{$404 \quad 4.3$ Biodiversity Sector}

The biodiversity sector uses metaphor to promote familiarity for the variety of stakeholders 406 involved in this catchment. Freshwater riverine ecosystem biodiversity, or FRED, is a central indicator in

407 ResiMod (see Figure 9) and was developed from an earlier indicator of aquatic biodiversity in the Kruger 408 National Park (KNP). In engagements with KNP representatives, the term FRED was suggested as a 409 "friendly" or neutral acronym aimed at more broadly representing aquatic biodiversity. Since the KNP 410 had played a significant role in the pursuit of penalty fines passed down to some companies following 411 one particularly damaging spill event (Centre for Environmental Rights (CER), 2016), theywished to avoid 412 politically and personally charged future discussions that might emerge if their interests were directly 413 named. Therefore, FRED was anthropomorphised (Figure 7) and presented within a short video to 414 support the biodiversity narrative. 


\subsubsection{Narrative}

FRED supports the delivery of a wide variety of ecosystem services. This includes household use and irrigation, as well as supporting freshwater biodiversity and ecotourism. FRED is impacted by excessive loads of sulphate and phosphate, reducing his ability to provide these services. FRED can recover as a result of remediation efforts as well as through natural processes, but these are both timeintensive (and costly) options. Therefore, ensuring the "health" of FRED is an immediate priority to ensure long-term sustainability and use of water.

423 Figure 8. Stock-flow structure of the Freshwater Riverine Ecosystem Diversity formulation, including use of species sensitivity 424 distributions.

\subsubsection{Structure and parameterization of the biodiversity sector.}

The biodiversity sector integrates the in-stream loads from WQSAM and the load calculated by

427 ResiMod. The "combined concentration..." variables calculate the total in-stream load using data from 428 WQSAM for pollutant loads (sulphate; phosphate) already in the river (in-stream load), with additions 429 from ResiMod sub-modules. The final concentration is calculated using WQSAM flow data. Thereafter 430 FRED is updated via the SSDs, that deliver the percentage of species affected at a given concentration. 431 FRED is therefore quantitatively represented as a percentage ranging from $0 \%$ (complete biodiversity 432 loss) to $100 \%$ (best ecological condition, "desired level of FRED") and indicates the proportion of FRED 433 that is intact (Figure 8). Historical data taken from WQSAM from 1950-2000 serves as the business as 434 usual (BAU), and WQSAM climate change ("CC") variables contain time series data generated from 2010 435 to 2060, which includes the downscaled GCM.

Three SSDs were implemented in ResiMod corresponding to the upper, central and lower 437 tendency values corresponding to the 95\% confidence interval (Vellemu et al., 2017). In order to 438 simulate worst- and best-case scenarios regarding impacts to biodiversity, the "conservation emphasis" 439 graphical lookups use the lower limit of the $95 \%$ confidence interval to assume the sharpest effect on 440 biodiversity. The "conservative" and "intermediate" use the upper bound and central tendency, 441 respectively. The "effect switches" allow the user to select the level of impact used in the simulation.

442 During a workshop with the conservation sector, stakeholders chose the "intermediate" sulphate and 443 "conservative" phosphate SSDs for the BAU simulation. 
The "conservation pressure on regulators due to FRED impacts" is a variable that is inversely related to impacts on FRED. It is an assumption made to represent the operational reality of the conservation sector's main leverage to enact change - in their role as a key-player applying pressure on regulators to initiate litigation of mining and industrial companies.

\subsection{Narratives and simulation using ResiMod}

The key narratives were developed according to each sector with substantial overlap across the sectors. This resulted fromthe narratives being shared within and between sectors throughout the development of ResiMod. These narratives were then synthesized into an overall systemic narrative that was used to frame the facilitated group work in a final workshop, conducted among representative stakeholders from all sectors.

Figure 9. The feedback loops identified within ResiMod. Yellow connections form feedback loops within the mining and industry submodule, green connections are feedback loops within the WWTW submodule, and the blue feedback loop is within the biodiversity submodule. Connections with double perpendicular lines indicate that delays are present in those feedback loops.

Figure 9 summarises the system structure of the final model indicating relationships and feedback loops corresponding to the structure of the final model. While WQSAM provided initial instream load conditions, endogenous behaviour driven by these feedbacks produces scenario results in response to parameter input. Scenario input was driven by stakeholders, as groups were tasked with making consensus decisions concerning which policy levers (middle of Figure 10 and in (red) italics in

463 Figure 9) ought to be modified in order to improve outcomes over the base case scenario. Before each 464 model simulation, stakeholders were asked to perform their own mental calculations (Ford, 1996) and 465 discuss potential outcomes. The CLD (Figure 9) was utilised as a tool to trace consequences of their 466 group decisions through overall feedbacks within the model. In this way, simulations were used to 467 challenge stakeholders' mental models and initiate discussions about the relationship between system 468 structure and simulated behaviour.

Simulation results for ResiMod are shown in Figure 10. Within the tradition of SD (and with 470 reference to the purpose of ResiMod described previously), verification was not pursued as point 471 predictions, but as qualitative assessment as to whether the model structure and resulting behaviour 472 patterns are qualitatively correct (Barlas, 1996). This falls within the scope of pattern-prediction and 
event-prediction tests (Forrester \& Senge, 1980). Due to the paucity of data for key indicators, the

474 model behaviour was verified primarily by stakeholder input.

The overall finding was that policies combining multiple mitigative actions are needed to combat freshwater biodiversity losses. Four scenarios are shown in an additive fashion (Figure 10):

477 FRED gradually declines under the BAU scenario, but the decline is sharper with climate change impacts. 478 Improvements to the management of the mining and industrial sector contribute significantly (scenario 4793 3) but systemic improvements (scenario 4) are most effective at improving FRED.

Figure 10. Simulation results for ResiMod displays examples of policy scenarios. Each run represents the corresponding scenario shown in the included table. Policy levers are visible in the middle panel, purple levers correspond to the mining and litigation sector, brown correspond to WWTW sector and green corresponds to the biodiversity sector. Lever descriptions are presented in detail on the online interface (https://exchange.iseesystems.com/directory/jai). Scenarios are additive: climate change incorporates changes detailed in Table 3; scenario 3 includes climate change plus 3 additional changes ( $a, b, c)$; scenario 4 adds additional parameter changes to WWTW $(a, b, c)$. The key indicator, FRED (panel A), is improved by reductions in mining tailings waste (lower left, panel B) and improvements to the function of WWTW (lower right, panel C). A prominent example of the interplay between policy levers and simulation results is noted by the vertical black bar in panel A at month 60 (year 5), where a marked increase in WWTW capacity is triggered by an increase in plant efficiency which becomes available in the selected "efficiency start year".

Participants experimented with policies by toggling parameters as a group, learning through simulation and discussion that combined actions were the most effective for improving FRED. For 495 example, simply increasing the efficiency of WWTW plants (i.e. a technological solution) was ineffective

496 without boosting investment in O\&M and reducing staff training times. This is because such a 497 combination of policies prevents the balancing loop controlling the online physical capacity of plants from drifting to low performance. However, some levers had little impact, even when applied in combination. For example, the "advocacy and public awareness" lever generated only minor 500 improvements in FRED. This is due both to the numerous long delays involved in these feedback loops, 501 and the low responsiveness of both WWTW and mining and industrial sectors to public awareness. 


\section{4.5 Parallel Evaluation using the Monitoring Evaluation Reporting and Learning}

503 Framework

504 Evaluation of the CoDyM program and ResiMod was conducted within the Monitoring, Evaluation,

505 Reporting and Learning (MERL) framework ongoing within RESILM-O (AWARD, 2017). MERL was

506 developed to improve evaluation and effectiveness of long-term programs carried out in complex

507 problem spaces. It is a parallel monitoring approach that uses both quantitative and qualitative methods

508 to continually assess the benefits or drawbacks of activities carried out within project activities and

509 adapt activities based on collective lessons learned (USAID, 2018). For CoDyM, a qualitative content

510 analysis approach was applied to all documents related to the project, including notes and meeting

511 minutes. This was a theory-driven coding exercise that reported the successes and limitations of the

512 approaches taken within CoDyM, including the unstructured interviews that delivered the narratives

513 along with the resulting utilisation of ResiMod within workshops.

The MERL evaluation indicated that the use of ResiMod in the final workshop was successful in 515 supporting the development of participants' understanding regarding climate change impacts on water

516 resources. Furthermore, participants commented on the beneficial nature of understanding the "system

517 as a whole" and having their mental models challenged. They were surprised that some variables had

518 less influence on simulated results than expected, leading them to reconsider the problem and consider

519 the validity of results more holistically. Communication techniques were also addressed by MERL, and

520 the presentation of different viewpoints via the synthesized narrative was regarded as an enjoyable

521 learning experience that helped some participants understand how other sectors think. It also left

522 participants feeling that their network had expanded (Kotschy, 2016). Selected comments from the

523 workshop further support these results:

524 - "I learned more about climate change and know its impacts on our waste water plants";

525 - "It was very interesting to note that climate change links to [other] sectors";

526 - "Making climate change practical and [finding] solutions on the ground [was valuable]";

527 - "The value of dynamic modelling to drive decisions and test results";

528 - "II] think that running this model and factoring in the climate change factor will improve horizon 529 planning and developing more resilient management plans"; 
- "... fabulous to dwell on the fact that climate change can be an opportunity - crises can be [a] kind [of] opportunity to coalesce around".

Overall, ResiMod was considered instrumental within CoDyM. As Kotschy (2016, p. 25) noted, "the value of [CoDyM] really lies in the possibility for developing a tool which can help stakeholders from different sectors to confront the impacts of their own practices and to explore options together". Moreover, the fact that representative stakeholders from each sector were present and engaged in the final workshop indicates that ours was a promising approach to support improved communication and learning among high-conflict groups, within data-scarce environments.

\section{Discussion, conclusions and future work}

This paper has demonstrated a novel approach using narratives to support SD model development and communication bi-directionally. This responded to the needs of the context and catchment and required trade-offs to engage a diverse stakeholder base with high-conflict potential, in a short timeframe and with limited data. One key strength of this work is the unique ability of SD to support integration of narratives with the flexible $\mathrm{M}^{3}$ participatory approach. This allowed a small modeling team operating in a high-conflict catchment to support stakeholder communication and facilitate insights about the impacts of climate change and what stakeholders could do about these impacts.

The case study catchment in South Africa is characterised by complex governance challenges impacted by multiple stressors, with multiple actors and high conflict potential. This same characterisation can describe many natural resource governance contexts around the globe. Therefore, the approach used to develop ResiMod, though not without limitations, can provide useful guidance for modelers and participatory SD practitioners in other settings. Narratives and storytelling are some of humanity's oldest communication methods. This study has shown how they can be successfully translated into a quantitative simulation model, with results made understandable to stakeholders with a history of conflict as well as differing technical acumen.

In some cases, the use of a simulation model limited the flexibility of the modeling team to respond to individual stakeholder needs (Kotschy, 2016). The erratic timing of stakeholder involvement (i.e. joining late or dropping out of the process), also added challenges. For example, the narrative surrounding the mining sector and possible actions was constructed with a paucity of input from the stakeholders until the later stages of model development. This created an unequal sharing of 
information and may have led to an overemphasis on the WWTW sector at earlier (and later) stages of model development and use. Furthermore, ResiMod did not become embedded in stakeholders' longterm decision-making, an ongoing challenge within participatory modeling and associated research (Halbe et al., 2018; Rouwette et al., 2002).

Nevertheless, this study has highlighted that understanding how to adapt participatory modeling processes and tools to stakeholders with different needs and technological backgrounds is crucial. Though this type of model customization can often be time and resource intensive, new technologies and strategies for stakeholder engagement that can develop aesthetically engaging interfaces may help close this gap (Fishwick, 2012). Narratives certainly offer another promising avenue to meet this challenge. Moreover, this study also explored how participatory approaches can help bring cutting-edge scientific information into the decision-making realm faster. For example, the incorporation of SSD curves for sulphate toxicity, which were available only as preliminary data during the development of ResiMod. Developing better theory on when and how to adapt stakeholder engagement processes will require the application of more targeted measurement and evaluation strategies (Zolfagharian et al., 2018). This can improve understanding of how participation, simulation and cutting-edge scientific knowledge can be better linked, and thereby shift scientists' role from dataproviders to facilitators of science-driven decision-making (McCown, 2001). One of the established and evolving sources for this are the evaluation methods applied to SD participatory modeling. With deference to narratives, a better evaluation of the effectiveness of the disconfirmatory interview at overcoming their persuasive nature is needed. Such studies could be undertaken within future applied cases or using controlled experimental settings.

\section{Acknowledgements}

This work was funded by the United States Agency for International Development: Southern Africa grant (RFA-674-12-000016 RESilience in the LIMpopo Basin Program (RESILIM). Input from participating stakeholders from government, industry, academia, and civil society - in addition to colleagues at AWARD - is gratefully acknowledged. We would also like to acknowledge Stephen Mallory and Dr. Tendai Sawunyama of IWR Water Research. 
587 Declaration of Interest

588 The authors declare no conflicts of interest.

589

590 


\section{References}

Akcil, A., \& Koldas, S. (2006). Acid Mine Drainage (AMD): causes, treatment and case studies. Journal of Cleaner Production, 14(12-13), 1139-1145. https://doi.org/10.1016/j.jclepro.2004.09.006

Alcamo, J. (2008). Chapter Six The SAS Approach: Combining Qualitative and Quantitative Knowledge in Environmental Scenarios. In Developments in Integrated Environmental Assessment (Vol. 2, pp. 123-150). https://doi.org/10.1016/S1574-101X(08)00406-7

Andersen, D. L., Luna-Reyes, L. F., Diker, V. G., Black, L., Rich, E., \& Andersen, D. F. (2012). The disconfirmatory interview as a strategy for the assessment of system dynamics models. System Dynamics Review, 28(3), 255-275. https://doi.org/10.1002/sdr.1479

Antunes, P., Kallis, G., Videira, N., \& Santos, R. (2009). Participation and evaluation for sustainable river basin governance. Ecological Economics, 68(4), 931-939. https://doi.org/10.1016/j.ecolecon.2008.12.004

Avraamidou, L., \& Osborne, J. (2009). The Role of Narrative in Communicating Science. International Journal of Science Education, 31, 1683-1707. https://doi.org/10.1080/09500690802380695

AWARD. (2017). Monitoring, Evaluation, Reporting and Learning for the USAID RESILIM-O Programme MERL FRAMEWORK Cooperative Agreement AID-674-A-13-00008.

Ba-Phalaborwa Municipality. (2015). Reviewed Final IDP Document 2013/14 - 2015/16.

Barlas, Y. (1996). Formal aspects of model validity and validation in system dynamics. System Dynamics Review, 12(3), 183-210. https://doi.org/10.1002/(SICI)1099-1727(199623)12:3<183::AIDSDR103>3.0.CO;2-4

Beall, A., Fiedler, F., Boll, J., \& Cosens, B. (2011). Sustainable water resource management and participatory system dynamics. Case study: Developing the palouse basin participatory model. Sustainability, 3(5), 720-742. https://doi.org/10.3390/su3050720

Carrim, A. H., Ceronio, A., \& Kruger, M. (2010). A Guide To Plant Evaluation and Optimisation. Proceedings, Water Institute of South Africa (WISA).

Carvalho, L., Mackay, E. B., Cardoso, A. C., Baattrup-Pedersen, A., Birk, S., Blackstock, K. L., Borics, G., Borja, A., Feld, C. K., Ferreira, M. T., Globevnik, L., Grizzetti, B., Hendry, S., Hering, D., Kelly, M., 
Langaas, S., Meissner, K., Panagopoulos, Y., Penning, E., ... Solheim, A. L. (2019). Protecting and restoring Europe's waters: An analysis of the future development needs of the Water Framework Directive. Science of the Total Environment, 658, 1228-1238. https://doi.org/10.1016/j.scitotenv.2018.12.255

Centre for Environmental Rights (CER). (2016). Zero hour: Poor Governance of Mining and the Violation of Environmental Rights in Mpumalanga (Issue May). https://cer.org.za/wpcontent/uploads/2016/06/Zero-Hour-May-2016.pdf

Clifford-Holmes, J. K., Carnohan, S. A., Biggs, H., Chihambakwe, K., \& Pollard, S. (n.d.). Fostering collective action through communicating system behavior and exploring long-term scenarios in the Olifants catchment of South Africa. Proceedings of the 4th Annual System Dynamics Conference in South Africa, 17-18 November 2017, (pp. 105-109).

Clifford-Holmes, J. K., Carnohan, S. A., Slinger, J. H., \& Palmer, C. (2017). HOW TO... engage with the challenges facing Water and Sanitation Services (WSS) in small municipalities. In Handbook No.5 (SP 120/18). Water Research Commission (WRC) project, K5/2248.

Clifford-Holmes, J. K., Pollard, S., Biggs, H., Chihambakwe, K., Jonker, W., York, T., Diaz, F. A., \& Slinger, J. H. (2016). Resilient by design: a modelling approach to support scenario and policy analysis in the Olifants River Basin, South Africa. PConference Proceedings of the 2016 International Conference of the System Dynamics Society. 17-21 July 2016, Delft, the Netherlands, (p.p. 578-586).

Clifford-Holmes, J. K., Slinger, J. H., de Wet, C., \& Palmer, C. G. (2018). Modelling in the 'Muddled Middle': A Case Study of Water Service Delivery in Post-Apartheid South Africa. In C. Garcia-Diaz \& C. Olaya (Eds.), Social Systems Engineering: The Design of Complexity (pp. 215-234). Wiley (ISBN: 978-1-118-97445-2). https://doi.org/10.1002/9781118974414.ch11

Climate System Analysis Group (CSAG). (2016). Advisory Report: Climate Scenarios for modelling the hydrological flow for the Ga-Selati Catchment.

Dahlstrom, M. F. (2014). Using narratives and storytelling to communicate science with nonexpert audiences. Proceedings of the National Academy of Sciences, 111(Supplement_4), 13614-13620. https://doi.org/10.1073/pnas.1320645111

Department of Water Affairs. (2011). 2011 Green Drop Report. 1-450. 
Requirements for the Purification of Waste Water or Effluent, 1 (1984) (testimony of Department of Water and Environmental Affairs).

Dippenaar, S., Moilwa, N., Olorunju, S., \& Visser, A. E. (2005). An analysis of the livelihoods of communities of the upper Selati catchment, South Africa.

Dowse, R., Tang, D., Palmer, C. G., \& Kefford, B. J. (2013). Risk assessment using the species sensitivity distribution method: Data quality versus data quantity. Environmental Toxicology and Chemistry, 32(6), 1360-1369. https://doi.org/10.1002/etc.2190

Eker, S., Zimmermann, N., Carnohan, S., \& Davies, M. (2018). Participatory system dynamics modelling for housing, energy and wellbeing interactions. Building Research and Information, 46(7), 738-754. https://doi.org/10.1080/09613218.2017.1362919

Fishwick, P. A. (2012). Hypermodelling: An integrated approach to dynamic system modelling. Journal of Simulation, 6(1), 2-8. https://doi.org/10.1057/jos.2011.16

Flyvbjerg, B. (2004). Phronetic planning research: Theoretical and methodological reflections. Planning Theory and Practice, 5(3), 283-306. https://doi.org/10.1080/1464935042000250195

Fontana, A., \& Frey, J. H. (2005). The Interview: From Neutral Stance to Political Involvement. In The Sage handbook of qualitative research, 3rd ed. (pp. 695-727). Sage Publications Ltd.

Ford, A. (1996). Testing the snake river explorer. System Dynamics Review, 12(4), 305-329. https://doi.org/10.1002/(SICI)1099-1727(199624)12:4<305::AID-SDR110>3.0.CO;2-4

Ford, A. (2010). Modeling the environment. In Island Press (2nd ed.). Island Press. https://books.google.com/books/about/Modeling_the_Environment_Second_Edition.html?id=38P JahZTzCOC\&source=kp_cover

Forrester, J. W., \& Senge, P. M. (1980). Tests for building confidence in system dynamics models. In TIMS Studies in the Management Sciences (Vol. 14, Issue 1, pp. 209-228).

Gopo, Q. N. (2013). Regulation of wastewater treatment plants in the Ba-Phalaborwa Municipality. December.

Guhathakurta, S. (2002). Urban Modeling as Storytelling: Using Simulation Models as a Narrative. Environment and Planning B: Planning and Design, 29(6), 895-911. 
674

675

676

677

678

679

680

681

682

683

684

685

686

687

688

689

690

691

692

693

694

695

696

697

698

699

Halbe, J., Pahl-Wostl, C., \& Adamowski, J. (2018). A methodological framework to support the initiation, design and institutionalization of participatory modeling processes in water resources management. Journal of Hydrology, 556, 701-716. https://doi.org/10.1016/j.jhydrol.2017.09.024

Hansen, K., \& Pollard, S. R. (2015). Status Quo of Wastewater Treatment in the Olifants River Basin.

Holness, S. (2014). Data report for RESLIM Olifants Livelihoods Study: Methods and summary of key data.

Houet, T., Marchadier, C., Bretagne, G., Moine, M. P., Aguejdad, R., Viguié, V., Bonhomme, M., Lemonsu, A., Avner, P., Hidalgo, J., \& Masson, V. (2016). Combining narratives and modelling approaches to simulate fine scale and long-term urban growth scenarios for climate adaptation. Environmental Modelling and Software, 86, 1-13. https://doi.org/10.1016/j.envsoft.2016.09.010

Jonker, W., York, T., \& Clifford-Holmes, J. K. (2015). ResiMod v.1. Modelling Process and Structure Report (Issue December).

Katz, Y. (2013). Against storytelling of scientific results. In Nature Methods (Vol. 10). https://doi.org/10.1038/nmeth.2699

Khan, S., Yufeng, L., \& Ahmad, A. (2009). Analysing complex behaviour of hydrological systems through a system dynamics approach. Environmental Modelling and Software, 24(12), 1363-1372. https://doi.org/10.1016/j.envsoft.2007.06.006

Kings, S. (2017). A river of shit, chemicals, metals flows through our land / News / Environment / M\&amp;G. Mail \& Guardian. https://mg.co.za/article/2017-04-13-00-a-river-of-shit-chemicalsmetals-flows-through-our-land

Koelble, T. A., \& Siddle, A. (2014). Decentralization in Post-Apartheid South Africa. Regional and Federal Studies, 00. https://doi.org/10.1080/13597566.2014.971773

Korsgaard, M. A., Schweiger, D. M., \& Sapienza, H. J. (1995). Building Commitment, Attachment, and Trust in Strategic Decision-Making Teams: The Role of Procedural Justice. Source: The Academy of Management Journal, 38(1), 60-84. https://doi.org/10.2307/256728

Kotschy, K. (2016). 2016 Evaluation Case Study: Collaborative Dynamic Modelling (CoDyM) to Support Scenario Thinking, Planning and Acting for Resilience. 
Krzywinski, M., \& Cairo, A. (2013). Storytelling. Nature Methods, 10(8). https://doi.org/10.1038/nmeth.2571

Kusangaya, S., Warburton, M. L., Archer van Garderen, E., \& Jewitt, G. P. W. (2014). Impacts of climate change on water resources in southern Africa: A review. Physics and Chemistry of the Earth, Parts A/B/C, 67-69, 47-54. https://doi.org/10.1016/j.pce.2013.09.014

Langsdale, S., Beall, A., Bourget, E., Hagen, E., Kudlas, S., Palmer, R., Tate, D., \& Werick, W. (2013). Collaborative modeling for decision support in water resources: Principles and best practices. Journal of the American Water Resources Association, 49(3), 629-638. https://doi.org/10.1111/jawr.12065

Lemaire, G. G., McKnight, U. S., Schulz, H., Roost, S., \& Bjerg, P. L. (2020). Evidence of spatio-temporal variations in contaminants discharging to a peri-urban stream. Groundwater Monitoring \& Remediation, gwmr.12371. https://doi.org/10.1111/gwmr.12371

Mallampalli, V. R., Mavrommati, G., Thompson, J., Duveneck, M., Meyer, S., Ligmann-Zielinska, A., Druschke, C. G., Hychka, K., Kenney, M. A., Kok, K., \& Borsuk, M. E. (2016). Methods for translating narrative scenarios into quantitative assessments of land use change. Environmental Modelling and Software, 82, 7-20. https://doi.org/10.1016/j.envsoft.2016.04.011

Manus, L., \& Van Der Merwe-Botha, M. (2010). Raising Wastewater Treatment Performance Through Incentive- \& Risk-Based Targeted Regulation. Proceedings, Water Institute of South Africa (WISA). http://www.ewisa.co.za/literature/files/350_266 Manus.pdf

McCown, R. L. (2001). Learning to bridge the gap between science-based decision support and the practice of farming: Evolution in paradigms of model-based research and intervention from design to dialogue*. Australian Journal of Agricultural Research, 52, 549-571.

Mehta, L., Alba, R., Bolding, A., Denby, K., Derman, B., Hove, T., Manzungu, E., Movik, S., Prabhakaran, P., \& Van Koppen, B. (2014). The politics of IWRM in Southern Africa. International Journal of Water Resources Development, 30(3), 528-542. https://doi.org/10.1080/07900627.2014.916200

Monks, T., Currie, C. S. M., Onggo, B. S., Robinson, S., Kunc, M., \& Taylor, S. J. E. (2019). Strengthening the reporting of empirical simulation studies: Introducing the STRESS guidelines. Journal of Simulation, 13(1), 55-67. https://doi.org/10.1080/17477778.2018.1442155 
Nozaic, D. J., \& Freese, S. D. (2009). Process Design Manual For Small Wastewater Works.

Oatley, K. (1999). Why fiction may be twice as true as fact: Fiction as cognitive and emotional simulation. Review of General Psychology, 3(2), 101-117. https://doi.org/10.1037/10892680.3.2.101

Olaya, C. (2015). Cows, agency, and the significance of operational thinking. System Dynamics Review, 31(4), 183-219. https://doi.org/10.1002/sdr.1547

Pahl-Wostl, C. (2015). Water Governance in the Face of Global Change. In Water Governance in the Face of Global Change: From Understanding to Transformation. Springer International Publishing. https://doi.org/10.1007/978-3-319-21855-7

Pollard, S., Biggs, H., \& Du Toit, D. R. (2014). A systemic framework for context-based decision making in natural resource management: reflections on an integrative assessment of water and livelihood security outcomes following policy reform in South Africa. Ecology and Society, 19(2), art63. https://doi.org/10.5751/ES-06312-190263

Pollard, S., \& du Toit, D. (2008). Integrated water resource management in complex systems: How the catchment management strategies seek to achieve sustainability and equity in water resources in South Africa. Water SA, 34(6), 671-679. http://www.wrc.org.za

Pollard, S., \& Laporte, A. (2015). Living in Phalaborwa: a collaborative view of the system through the eyes of people.

Pollard, S. R., Retief, H., \& Clifford-Holmes, J. K. (2020). Systemic, social learning approaches to water governance and sustainability in the Olifants River Catchment.

Richardson, G. P. (2013). Concept models in group model building. System Dynamics Review, 29(1), 4255. https://doi.org/10.1002/sdr.1487

Rinklebe, J., Shaheen, S. M., \& Yu, K. (2016). Release of As, Ba, Cd, Cu, Pb, and Sr under pre-definite redox conditions in different rice paddy soils originating from the U.S.A. and Asia. Geoderma, 270, 21-32. https://doi.org/10.1016/j.geoderma.2015.10.011

Rouwette, E. A. J. A., Vennix, J. A. M., \& van Mullekom, T. (2002). Group model building effectiveness : a review of assessment studies + . 18(1), 5-45. https://doi.org/10.1002/sdr.229 
Schulze, R. E. (2011). Approaches towards practical adaptive management options for selected waterrelated sectors in South Africa in a context of climate change. Water SA, 37(5), 621-646. https://doi.org/10.4314/wsa.v37i5.1

Schulze, R. E., \& Davis, N. S. (2019). Development of a Framework and Methodology for Undertaking a Risk and Vulnerability Assessment in All Nine Water Management Areas of South Africa. Practitioners' Handbook for Undertaking Current and Projected Future Climate Related Risk And Vulnerability Modelling Assessments., Schulze and Associates, Pietermaritzburg, Report to GIZ, Pretoria.

Scott, Rodney J., Cavana, R. Y., \& Cameron, D. (2014). Mechanisms for Understanding Mental Model Change in Group Model Building. Systems Research and Behavioral Science, 33(1), 100-118. https://doi.org/10.1002/sres.2303

Scott, Rodney James, Cavana, R. Y., \& Cameron, D. (2016). Recent evidence on the effectiveness of group model building. European Journal of Operational Research, 249(3), 908-918. https://doi.org/10.1016/j.ejor.2015.06.078

Slaughter, A. R. (2017). Simulating Microbial Water Quality in Data-Scarce Catchments: an Update of the WQSAM Model to Simulate the Fate of Escherichia coli. Water Resources Management, 31(13), 4239-4252. https://doi.org/10.1007/s11269-017-1743-1

Slaughter, A. R., \& Hughes, D. A. (2013). A simple model to separately simulate point and diffuse nutrient signatures in stream flows. Hydrology Research, 44(3), 538. https://doi.org/10.2166/nh.2012.213

Slaughter, A. R., Hughes, D. A., Retief, D. C. H., \& Mantel, S. K. (2017). A management-oriented water quality model for data scarce catchments. Environmental Modelling and Software, 97, 93-111. https://doi.org/10.1016/j.envsoft.2017.07.015

Sonne, A. T., McKnight, U. S., Rønde, V., \& Bjerg, P. L. (2017). Assessing the chemical contamination dynamics in a mixed land use stream system. Water Research, 125, 141-151. https://doi.org/10.1016/j.watres.2017.08.031

Sonne, A. T., Rasmussen, J. J., Höss, S., Traunspurger, W., Bjerg, P. L., \& McKnight, U. S. (2018). Linking ecological health to co-occurring organic and inorganic chemical stressors in a groundwater-fed 
stream system. Science of The Total Environment, 642, 1153-1162.

https://doi.org/10.1016/j.scitotenv.2018.06.119

Statistics South Africa. (2011). Ba-Phalaborwa Municipality Census Data. http://www.statssa.gov.za/?page_id=993\&id=ba-phalaborwa-municipality

Stave, K. A. (2003). A system dynamics model to facilitate public understanding of water management options in Las Vegas, Nevada. Journal of Environmental Management, 67(4), 303-313. https://doi.org/10.1016/S0301-4797(02)00205-0

Sterman, J. (2000). Business dynamics : systems thinking and modeling for a complex world. Irwin/McGraw-Hill.

Tsoukas, H., \& Hatch, M. J. (2001). Complex thinking, complex practice : The case for a narrative approach to organizational complexity. 54(8), 979-1013. https://doi.org/0018-7267

USAID. (2018). Complexity-Aware Monitoring Discussion Note (Brief). https://usaidlearninglab.org/library/complexity-aware-monitoring-discussion-note-brief

van den Belt, M., \& Blake, D. (2015). Mediated Modeling in Water Resource Dialogues Connecting Multiple Scales. Journal of the American Water Resources Association, 51(6), 1581-1599. https://doi.org/10.1111/1752-1688.12330

Vellemu, E. C., Mensah, P. K., Griffin, N. J., Odume, O. N., Palmer, C. G., \& Dowse, R. (2017). The sensitivity of five freshwater species to sulphates: A major salt component in acid mine drainage. Mine Water and the Environment Journal, (in press).

Vennix, J. A. M. (1996). Group Model Building. Wiley.

Vennix, J. A. M. (1999). Group model-building : tackling messy problems. System Dynamics Review, 15(4), 379-401.

Voinov, A., Jenni, K., Gray, S., Kolagani, N., Glynn, P. D., Bommel, P., Prell, C., Zellner, M., Paolisso, M., Jordan, R., Sterling, E., Schmitt Olabisi, L., Giabbanelli, P. J., Sun, Z., Le Page, C., Elsawah, S., BenDor, T. K., Hubacek, K., Laursen, B. K., ... Smajgl, A. (2018). Tools and methods in participatory modeling: Selecting the right tool for the job. Environmental Modelling and Software, 109(August), 232-255. https://doi.org/10.1016/j.envsoft.2018.08.028 
810 Vörösmarty, C. J., Mclntyre, P. B., Gessner, M. O., Dudgeon, D., Prusevich, A., Green, P., Glidden, S., 811 Bunn, S. E., Sullivan, C. A., Liermann, C. R., \& Davies, P. M. (2010). Global threats to human water 812 security and river biodiversity. Nature, 467(7315), 555-561. https://doi.org/10.1038/nature09440

813 Winz, I., Brierley, G., \& Trowsdale, S. (2009). The use of system dynamics simulation in water resources 814 management. Water Resources Management, 23(7), 1301-1323. https://doi.org/10.1007/s11269$815 \quad 008-9328-7$

816 World Economic Forum. (2020). The Global Risks Report 2020.

817 Ziervogel, G., New, M., Archer Van Garderen, E., Midgley, G., Taylor, A., Hamann, R., Stuart-Hill, S., 818 Myers, J., \& Warburton, M. (2014). Climate change impacts and adaptation in South Africa. WIREs 819 Clim Change, 5, 605-620. https://doi.org/10.1002/wcc.295

820 Zolfagharian, M., Romme, A. G. L., \& Walrave, B. (2018). Why, when, and how to combine system 821 dynamics with other methods: Towards an evidence-based framework. Journal of Simulation, 822 12(2), 98-114. https://doi.org/10.1080/17477778.2017.1418639

823 